\title{
Discontinuous hindcast simulations of estuarine bathymetric change: A case study from Suisun Bay, California
}

\author{
Neil K. Ganju ${ }^{\mathrm{a}, *}$, Bruce E. Jaffe ${ }^{\mathrm{b}}$, David H. Schoellhamer ${ }^{\mathrm{c}, \mathrm{d}}$ \\ ${ }^{a}$ U.S. Geological Survey, 384 Woods Hole Road, Woods Hole, MA 02543, USA \\ ${ }^{\mathrm{b}}$ U.S. Geological Survey, 400 Natural Bridges Drive, Santa Cruz, CA 95060, USA \\ ${ }^{\mathrm{c}}$ U.S. Geological Survey, 6000 J Street, Sacramento, CA 95819, USA \\ ${ }^{\mathrm{d}}$ Department of Civil and Environmental Engineering, University of California, Davis, USA
}

\section{A R T I C L E I N F O}

\section{Article history:}

Received 30 November 2010

Accepted 6 April 2011

Available online 15 April 2011

\section{Keywords:}

estuarine geomorphology

sediment transport

modeling

hindcasting

\begin{abstract}
A B S T R A C T
Simulations of estuarine bathymetric change over decadal timescales require methods for idealization and reduction of forcing data and boundary conditions. Continuous simulations are hampered by computational and data limitations and results are rarely evaluated with observed bathymetric change data. Bathymetric change data for Suisun Bay, California span the 1867-1990 period with five bathymetric surveys during that period. The four periods of bathymetric change were modeled using a coupled hydrodynamic-sediment transport model operated at the tidal-timescale. The efficacy of idealization techniques was investigated by discontinuously simulating the four periods. The 1867-1887 period, used for calibration of wave energy and sediment parameters, was modeled with an average error of 37\% while the remaining periods were modeled with error ranging from $23 \%$ to $121 \%$. Variation in postcalibration performance is attributed to temporally variable sediment parameters and lack of bathymetric and configuration data for portions of Suisun Bay and the Delta. Modifying seaward sediment delivery and bed composition resulted in large performance increases for post-calibration periods suggesting that continuous simulation with constant parameters is unrealistic. Idealization techniques which accelerate morphological change should therefore be used with caution in estuaries where parameters may change on sub-decadal timescales. This study highlights the utility and shortcomings of estuarine geomorphic models for estimating past changes in forcing mechanisms such as sediment supply and bed composition. The results further stress the inherent difficulty of simulating estuarine changes over decadal timescales due to changes in configuration, benthic composition, and anthropogenic forcing such as dredging and channelization.
\end{abstract}

Published by Elsevier Ltd.

\section{Introduction}

Estuarine bathymetric changes over decadal timescales are relevant to ecological function, contaminant transport, navigation and habitat restoration. Changes in external forcing including sealevel, freshwater flow and watershed sediment supply prevent or retard estuaries from reaching quasi-equilibrium in terms of sediment balance. In order to address this behavior, geomorphic modeling has been used in recent times in an attempt to straddle simulation and predictive exploration. Estuarine geomorphic models with timescales of years to decades and spatial scales of $\sim 100 \mathrm{~m}$ are run on shorter timescales resolving tidal flows and discrete wind-wave events, with morphological changes accelerated

\footnotetext{
* Corresponding author

E-mail address: nganju@usgs.gov (N.K. Ganju).
}

using a morphological acceleration factor (MF). Small sediment mass fluxes can be scaled up by some constant MF without greatly changing the depth and hydrodynamics, thereby accelerating morphological change with no increase in computational time.

A large range of morphological acceleration factors has been used in prior work; for these the computational stability criterion requires that the bed Courant number be less than one (Hibma et al., 2003; Van der Wegen and Roelvink, 2008). A possible complication of this condition arises in applications with episodic (inter-annual) forcing on a timescale shorter than the simulated period. In simulations with tidal forcing alone, Lesser et al. (2004) found minor differences between the simulation of 280 tides $(\mathrm{MF}=20)$ and 56 tides $(\mathrm{MF}=100)$. In contrast, preliminary simulations of Suisun Bay in California (Ganju et al., 2009) yielded substantial differences between simulations of $20 \mathrm{y}$ of morphologic change that simulated one year with $\mathrm{MF}=20$ and two years with $\mathrm{MF}=10$. This difference is due to the inter-annually varying signals 
of freshwater flow, wind-waves and seaward sediment concentration in those simulations. The limitations of this type of modeling in capturing bathymetric changes were demonstrated by Ganju et al. (2009). While net bathymetric change in the basin could be maintained, changes along estuarine cross-sections were more difficult to reproduce.

The purpose of this study is to evaluate the efficacy of morphological simulation techniques in estuarine systems with variable conditions over the decadal timescale. Specific parameters that may change over this timescale include streamflow, seaward sediment supply, bed shear strength and density, and upstream sediment trapping. Suisun Bay, California, has undergone substantial changes in sediment supply, freshwater flow and configuration, and offers a suitable test case to test these methods. Suisun Bay was surveyed over four sub-periods during 1867-1990 (Cappiella et al., 1999) providing a rare data set with which to test geomorphic modeling techniques.

Modeling overall decadal-scale bathymetric changes requires methods for idealizing processes and selecting parameter values. Major idealized processes for this study include a synthetic seaward SSC boundary condition and wind speed and direction. Parameter values such as those for sediment bed characteristics are determined over a calibration period but do not necessarily remain static. Application of morphological acceleration and morphological hydrograph to Suisun Bay requires discontinuous simulation of the overall 1867-1990 period due to changes in forcing. Constant morphological acceleration can only be applied over a period when forcing (e.g., tidal, wind, sediment load) may be assumed to remain reasonably constant. Morphological hydrograph, which is a reduced set of freshwater flow hydrographs, cannot be assumed to remain constant due to changes in climate and water management. Anthropogenic changes in estuarine configuration, e.g., due to dredging, diking and filling, also require step changes in the modeling domain. Benthic invasions may also change the behavior of the sediment bed.

Ganju et al. (2009) used this morphological acceleration and hydrograph approach for simulations of bathymetric change in Suisun Bay during the 1867-1887 period, and established that the technique can be applied with satisfactory performance. Bathymetric changes were shown to be sensitive to the combination of simulation time and morphological acceleration factor. For the 1867-1887 period, a simulation time of $1 \mathrm{y}$ with $\mathrm{MF}=20$ gave satisfactory performance. However, the remaining surveys span irregular intervals: 35 y (1887-1922), 20 y (1922-1942), and 48 y (1942-1990). These three periods, for which it is essential to assign the appropriate simulation time and MF (for the two non-20 y simulations), provide an opportunity for testing combinations of simulation time and morphological acceleration. In the subsequent sections we describe Suisun Bay, the bathymetric change data, geomorphic model development and application for each simulated period, and discuss specific and general implications of the simulations.

\section{Site description}

Suisun Bay is the landward-most subembayment of San Francisco Bay and spans from the Sacramento-San Joaquin River Delta at the landward end to Carquinez Strait at the seaward end (Fig. 1). The majority of the bay is shallower than $5 \mathrm{~m}$ at meanlower-low-water (MLLW) with several deeper $(>10 \mathrm{~m})$ channels which run longitudinally through the bay. Tides are mixedsemidiurnal with a $2 \mathrm{~m}$ range during spring tides; currents approach $1 \mathrm{~m} / \mathrm{s}$ in the channels. Grizzly and Honker Bays are the largest expanses of shallow water, situated on the northern edge of the main channels. The seasonal sediment transport cycle begins in winter with large freshwater flows; some sediment deposits in the Delta while the remaining sediment is exported through Suisun Bay to San Pablo Bay (Wright and Schoellhamer, 2005). Persistent onshore winds during spring and summer generate wind-waves resuspending bed sediments in both Suisun and San Pablo Bays (Ruhl and Schoellhamer, 2004). Landward sediment transport from San Pablo Bay to Suisun Bay is the result of a strong SSC gradient due to wind-wave resuspension in San Pablo Bay (Ganju and Schoellhamer, 2006). Sediment supply from the ocean is minimal compared to supply from San Pablo Bay (Schoellhamer et al., 2005).

\section{Bathymetric change data}

Cappiella et al. (1999) modeled bathymetric surveys of Suisun Bay performed in 1867, 1887, 1922, 1942, and 1990. A continuous

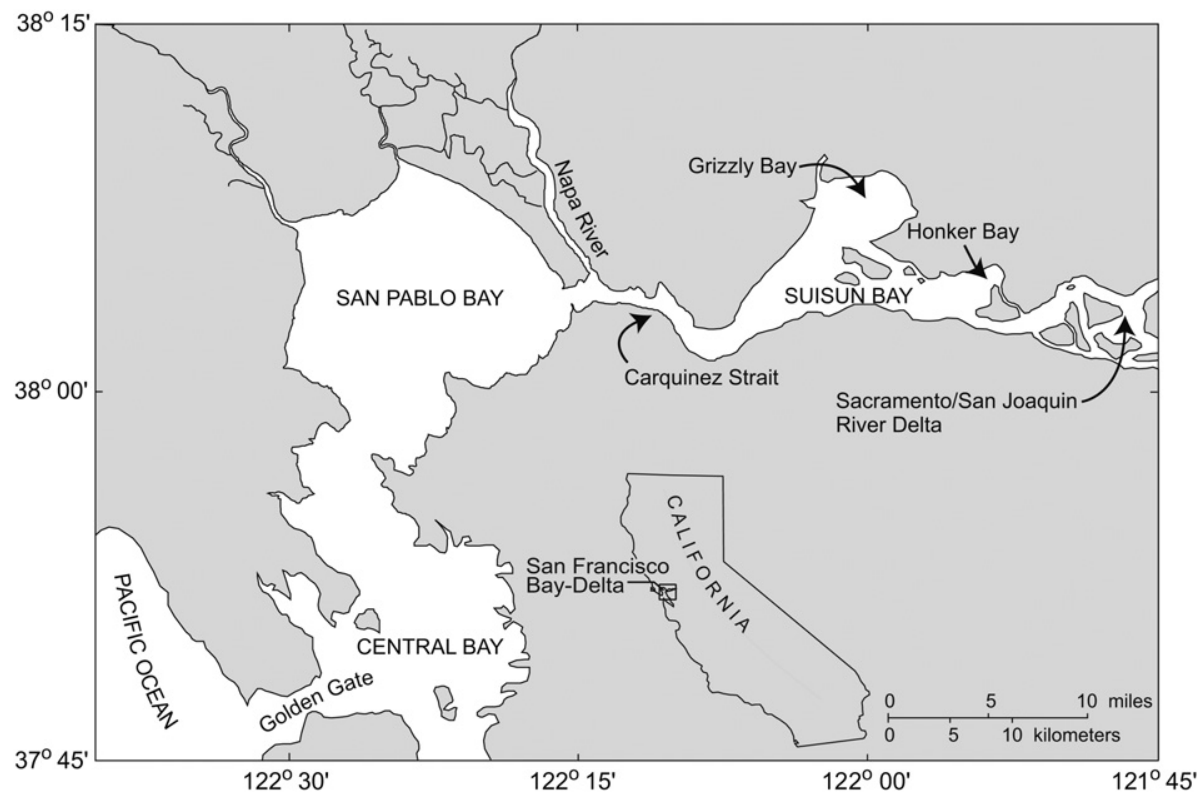

Fig. 1. Northern San Francisco Bay. Suisun Bay is the landward-most subembayment, adjacent to the Sacramento/San Joaquin River Delta. 
surface representation (surface grid) of each bathymetry survey was created from depth soundings and contours using Topogrid (Wahba, 1990). Four change grids were created by taking the difference between the bathymetric grids for each consecutive survey year (i.e., 1887 survey - 1867 survey $=1867-1887$ change grid). These bathymetric change grids display erosion and deposition and were used to calculate actual volumes of sediment eroded or deposited once vertical and horizontal corrections were applied to bring surveys to a common datum (MLLW). The grids were used to identify patterns of change as well as to calculate sedimentation rates and net volume change for each time period.

From 1867 (the year of the earliest detailed hydrographic survey of the area) until at least 1887, Suisun Bay was depositional in nature and much of the sediment deposited was hydraulic mining debris created by extensive gold excavation in the Sierra Nevada Mountains. During this time period, approximately $115 \mathrm{Mm}^{3}$ of sediment was deposited in the study area. This is equivalent to about $0.025 \mathrm{~m} / \mathrm{y}$ accumulation over all of Suisun Bay or a 15\% reduction in water volume over the $20 \mathrm{y}$ period. Just under twothirds of the area of Suisun Bay was depositional from 1867 to 1887 while less than one-third of it was erosional. From 1887 to 1990 Suisun Bay was erosional due to a decrease in sediment supply to the bay. This decrease was largely due to the cessation of hydraulic mining in 1884 and the increase in water management projects during the 20th century. The actual volume of erosion increased slightly during each change period from 1887 to 1990. From 1887 to 1990 approximately $262 \mathrm{Mm}^{3}$ of sediment were eroded from the bay, which is equivalent to $0.012 \mathrm{~m} / \mathrm{y}$ over the entire study area. Over the entire study period Suisun Bay had a net loss of over $100 \mathrm{Mm}^{3}$ of sediment, which is equivalent to a loss of $0.74 \mathrm{~m}$ over the entire Suisun Bay area. These large signals of bathymetric change likely outweigh possible errors in the bathymetric estimates and provide a testing opportunity for estuarine geomorphic models.

\section{Hydrodynamic/sediment transport modeling}

The Regional Ocean Modeling System (Shchepetkin and McWilliams, 2005) is a public-domain hydrodynamic model coupled with the Community Sediment Transport Model (Warner et al., 2008). The full details of the numerical implementation are beyond the scope of this work. The reader is directed to several primary sources as well as the open source code itself (www. myroms.org) for model details. Details of the sediment transport model can be found in Warner et al. (2008). Implementation of the model with regards to Suisun Bay is detailed in Ganju et al. (2009).

Model parameters (Table 1 ) for these simulations were determined by Ganju et al. (2009) using the 1867-1887 period as a calibration data set. For subsequent simulations as performed here we held the values constant. Errors involved with the constant parameters are discussed in Section 6, where parameters were varied to improve performance. Greater detail regarding analytical formulations, development of boundary conditions, and wetting/ drying can be found in Ganju et al. (2009). Here we discuss the main idealizations of the domain, boundary conditions, and timestepping.

\subsection{Modeling domain}

The modeling domain of Suisun Bay is constrained between Carquinez Strait on the seaward end and the Delta on the landward end. The domain was discretized into a $160 \times 87 \times 4$ cell domain (in the west-east, north-south, and vertical directions respectively). Simplification of the Delta was accomplished by representing the Delta as a uniform channel as detailed in Ganju and Schoellhamer
Table 1

Model parameters for decadal-timescale simulations. Values marked with an asterisk were varied for calibration.

\begin{tabular}{|c|c|}
\hline Model parameter & Value \\
\hline$\#$ of $x$-direction cells, size range & $160,72-394 \mathrm{~m}$ \\
\hline \# of $y$-direction cells, size range & $87,102-593 \mathrm{~m}$ \\
\hline \# of $z$-direction cells & 4 \\
\hline Baroclinic time step & $40 \mathrm{~s}$ \\
\hline Barotropic time step & $2 \mathrm{~s}$ \\
\hline Simulation steps & Various \\
\hline Settling velocity & $0.10 / 0.25 \mathrm{~mm} \mathrm{~s}^{-1}$ \\
\hline Erosion rate & $2 \times 10^{-5} \mathrm{~kg} \mathrm{~m}^{-2} \mathrm{~s}^{-1}$ \\
\hline Bed critical shear stresses* & $0.15 / 1.05 \mathrm{~N} \mathrm{~m}^{-2}$ \\
\hline Porosity & 0.60 \\
\hline Bed density & $2000 \mathrm{~kg} \mathrm{~m}^{-3}$ \\
\hline Initial bed thickness & $2.0 \mathrm{~m}$ \\
\hline Wave period* & $1.425 \mathrm{~s}$ \\
\hline Wave fetch & $20 \mathrm{~km}$ \\
\hline Water depth (for wave model) & Evolving bathymetry \\
\hline Tidal boundary velocity, stage & Flather (radiation) \\
\hline River boundary velocity, stage & Flather (radiation) \\
\hline Tidal boundary tracers & Clamped \\
\hline River boundary tracers & Clamped \\
\hline Morphological acceleration factor & Various (range: $17.5-24$ ) \\
\hline
\end{tabular}

(2009). The Suisun Bay bathymetric grids were interpolated to a curvilinear, orthogonal grid of the same resolution as was used in the previous modeling efforts. The shape, depths, and trapping efficiency of the actual Delta have varied over the last 150 years (Thompson, 1957) however there are no detailed data of this type. The lack of precise configurational and bathymetric data for an important component of the system ultimately leads to an uncertainty and estimation which can result in error.

\subsection{Boundary conditions}

\subsubsection{Landward boundary conditions}

Simulating historical periods requires some method for estimating freshwater flows and sediment loads. Ganju et al. (2008) developed a daily time-series of freshwater flow and sediment load using two historical proxies (monthly rainfall and unimpaired flow magnitudes) to generate daily time-series of flows and sediment loads to the Sacramento/San Joaquin Delta for the 1851-1929 period. Extensive details of this procedure can be found in Ganju et al. (2008). We used these data for the 1887-1922 period; for the 1922-1990 period we used a combination of the Ganju et al. (2008) data and measured flow and sediment load data (waterdata.usgs.gov/nwis). Both the reconstructed and observed records indicate an ongoing reduction in watershed sediment supply to the Delta, beginning in the early 20th century (Fig. 2).

\subsubsection{Seaward boundary conditions}

Tidal harmonics $\left(\mathrm{K}_{1}, \mathrm{O}_{1}, \mathrm{M}_{2}, \mathrm{~S}_{2}\right)$ provided an appropriate initial estimate of historic tidal elevations and velocities (Gartner, 1997) while salinity was estimated using the method of Warner et al. (2005). This is an analytical function that relates the seaward salinity gradient to freshwater flow. Details of this function, for Suisun Bay applications, are described by Ganju et al. (2009). This method accounts for the estuarine response to freshwater flow in a physically consistent manner, and can be extrapolated to other periods with little error (barring a change in tidal prism or channel geometry).

Landward sediment transport is an important component of the sediment supply to Suisun Bay (Ganju and Schoellhamer, 2006) and other multi-embayment estuaries with seasonal sediment transport patterns. During summer months with low freshwater flow and persistent winds there is a gradient in SSC from San Pablo to 


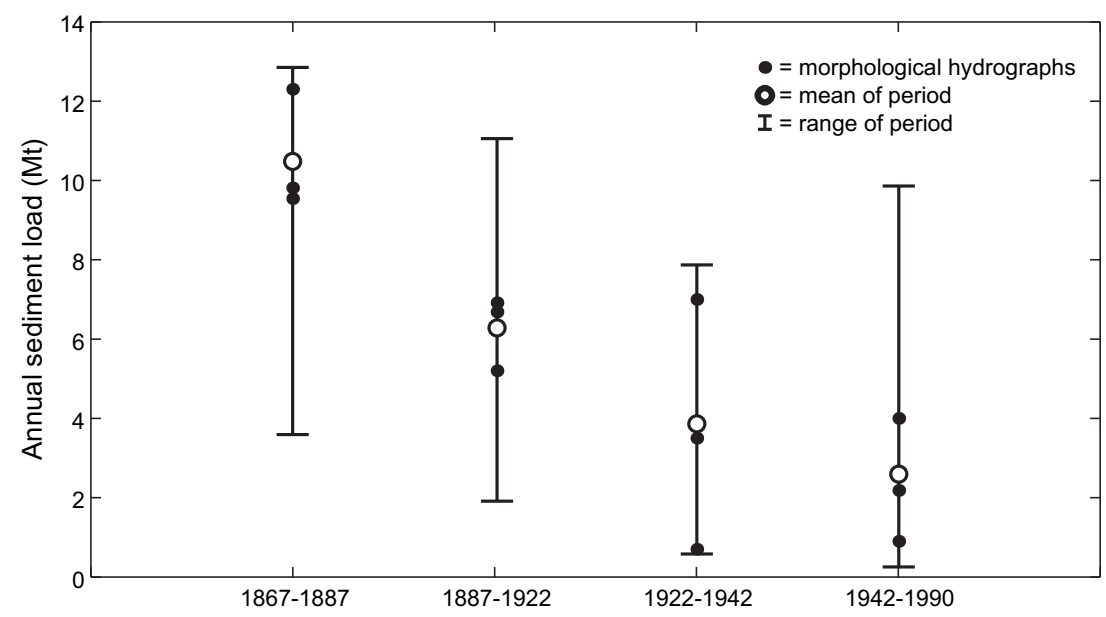

Fig. 2. Mean and range of annual sediment loads over each simulation period from Ganju et al. (2008), with sediment loads of each morphological hydrograph.

Suisun Bay. This leads to landward dispersive fluxes as flood-tide in Suisun Bay is correlated with higher SSC. Therefore a seaward SSC boundary condition is necessary for Suisun Bay. Ganju and Schoellhamer (2009) developed a synthetic SSC boundary condition based on measured flood-tide SSC at Carquinez Strait landward of the Napa River (Buchanan and Ganju, 2005). Three signals were superimposed to recreate a synthetic time-series of SSC: a flow signal that peaks in the early spring, a seasonal wind-wave signal that peaks in the summer, and a spring-neap signal that is a function of tidal energy (obtained from tidal harmonics). The timeseries was then modulated by a mean yearly SSC which is linearly related to total sediment input from the Delta during the water year.

\subsubsection{Sediment transport and bed parameters}

Suspended-sediment transport is calculated with the advection-diffusion equation. A source term representing bed erosion is given by Ariathurai and Arulanandan (1978) as:

$C_{\text {source }}=\epsilon_{S}(1-n)\left(\frac{\tau_{w}}{\tau_{c}}-1\right)$ for $\tau_{w}>\tau_{c}$

where $\epsilon_{s}$ is the erosion rate constant, $n$ is the bed porosity, $\tau_{w}$ is the shear stress exerted on the bed, and $\tau_{c}$ is the critical shear strength of the sediment bed. The sediment sink term, deposition, is given by

$C_{\text {sink }}=\frac{\partial w_{s} C}{\partial S}$

where $w_{s}$ is the bulk settling velocity of the size class (the differential operator is required due to the $s$-coordinate system). Multiple bed layers may be specified, with each layer composed of a user-specified mixture of sediment classes. The properties of the mixed class bed, such as shear strength, are weighted using the average mass fractions of the classes. The details of the bed layer model are given by Warner et al. (2008). Calculation of bed stresses is performed using wave-current interaction (Madsen, 1994), as implemented by Warner et al. (2008); they detail the bottomboundary layer module and the other modes available. Wavegenerated bottom orbital velocities are specified by providing spatially and temporally varying significant wave heights, directions, and periods. Bottom orbital velocities are calculated using the approximation of Dean and Dalyrymple (1991) within the bottomboundary layer module. Specification of wave height, direction, and period is discussed below.
Specifying initial sediment bed distributions are critical for avoiding spin-up errors as the bed evolves into a dynamic equilibrium with the hydrodynamic conditions. The 1867-1887 simulations utilized two sediment classes: a weak and strong fraction (in terms of critical erosion shear stress). These classes aim to represent silt and sand fractions present in the bed. These fractions were initialized as described in Ganju et al. (2009) and used as a calibration parameter. For these ensuing simulations we used a semilog relationship between the final sediment distribution and water depth generated using the results from the previous simulation. For example the 1887-1922 simulations were initialized using the final sediment distribution and depth results from the 1867-1887 simulations. We used a simple relationship to avoid overspecification of sediment distribution during a period with no corroborating data. In general, sediment distributions coarsened (strong fraction dominant) with time. This method is similar to that employed by Van der Wegen et al. (2010) who found that allowing for a spin-up of bed composition led to more representative geomorphic evolution.

\subsubsection{Atmospheric forcing}

Wind-wave resuspension is an important sediment transport mechanism in estuaries and can impose a large seasonal signal on geomorphic change. Most systems have some combination of episodic (storm) and seasonal wind forcing; in Suisun Bay we have ignored the episodic signal. A synthetic time-series of wind forcing based on spectral analysis of measured data was developed using seasonal, weekly, and daily wind signals (Ganju et al., 2009). The wind speed was provided to the model which then calculated the fetch-limited wave height using the Shore Protection Manual method (Coastal Engineering Research Center, 1984). For simplicity wave direction is held constant at $270^{\circ}$ which is the predominant wind direction. Water depth was utilized in this computation using the evolving bathymetry and water surface elevation. This accounted for feedback between geomorphic evolution and waveinduced bottom stress which is important in shallow estuarine systems.

\subsection{Idealized time-stepping: morphological hydrograph and morphological acceleration factor}

We used morphological hydrographs (MHs; Ganju et al., 2009) to reduce the set of required freshwater hydrographs. The bathymetric changes from each simulation (with a specific $\mathrm{MH}$ ) were 
then combined to yield a simulation that ostensibly represented the total bathymetric change. Three MHs were simulated separately and the bathymetric changes averaged to represent the entire period (Fig. 2). Ganju and Schoellhamer (2010) showed that morphological hydrographs with lower flow tended to encourage landward sediment transport in deeper channels, while higher flow hydrographs exported sediment seaward. Higher flows resulted in greater deposition over shoals as compared to lower flows under identical wind-wave forcing.

The other essential idealization is the use of a morphological acceleration factor (MF; Lesser et al., 2004; Roelvink, 2006) which accelerates bed changes within the model. Details of the ROMS implementation are given in Warner et al. (2008). At each time step the calculated bed sediment fluxes are scaled up by the factor to produce an accelerated bed change. For the 1867-1887 period, a simulation time of $1 \mathrm{y}$ with $M F=20$ (along with other model parameters) gave satisfactory performance (Ganju et al., 2009). However, the remaining surveys span irregular intervals: $35 \mathrm{y}$ (1887-1922), 20 y (1922-1942), and 48 y (1942-1990). For each of these periods we determined appropriate simulation time and $M F$ (for the two non-20 y simulations).

\subsection{Selection of performance goals}

Following Ganju et al. (2009), we established several metrics for performance: accurate representation of net vertical deposition within the entirety of Suisun Bay, and accurate representation of net vertical erosion or deposition in specific depth ranges. Satisfying the net bed level change in specific depth ranges will necessarily satisfy the net bed level change over the whole domain. The majority of Suisun Bay is shallower than $2 \mathrm{~m}$ and we sought to primarily minimize error in this depth interval. Following Sutherland et al. (2004) and Ganju et al. (2009) we also use the Brier Skill Score (BSS; Murphy and Epstein, 1989) to evaluate model performance. The Brier Skill score equals one for perfect agreement, zero for skill equivalent to assuming no change in geomorphology, and negative for predictive skill worse than the assumption of no change. Prior work (Sutherland et al., 2004) established scores greater than 0.2 to be "fair" for geomorphic simulations.

\section{Results}

\subsection{Bathymetric change: $1887-1922$}

For a $35 \mathrm{y}$ period, the simulation was performed with $1 \mathrm{y}$ simulation time and $M F=35$, or a 2 y simulation time and $M F=17.5$. These two simulations produced similar skill scores for both the 0-2 $\mathrm{m}$ interval and the entire estuary (BSS $=0.24$ ). However, the $2 \mathrm{y}, M F=17.5$ simulation produced better estimates of net deposition in the $0-2 \mathrm{~m}$ interval and the entire estuary. This suggests that increasing the simulation time and reducing the acceleration factor brings modeled change closer to observed change as expected. The $2 \mathrm{y}$ simulation incorporates two full annual cycles of freshwater sediment supply and wind-wave resuspension and reduces the nonlinear effects between these signals and the morphological acceleration factor.

Qualitatively, the modeled changes appear reasonable for the majority of Honker Bay, the seaward edge of Honker Bay, and portions of the seaward main channel (Fig. 3). The idealized wave model (constant direction) may account for areas of poorer agreement, mainly the landward end of Honker Bay and the western edge of Grizzly Bay. Wave propagation into those bays from deeper waters will alter wave direction, height, and period; the parameterization used here only varies wave height (as a function of water depth and wind speed).
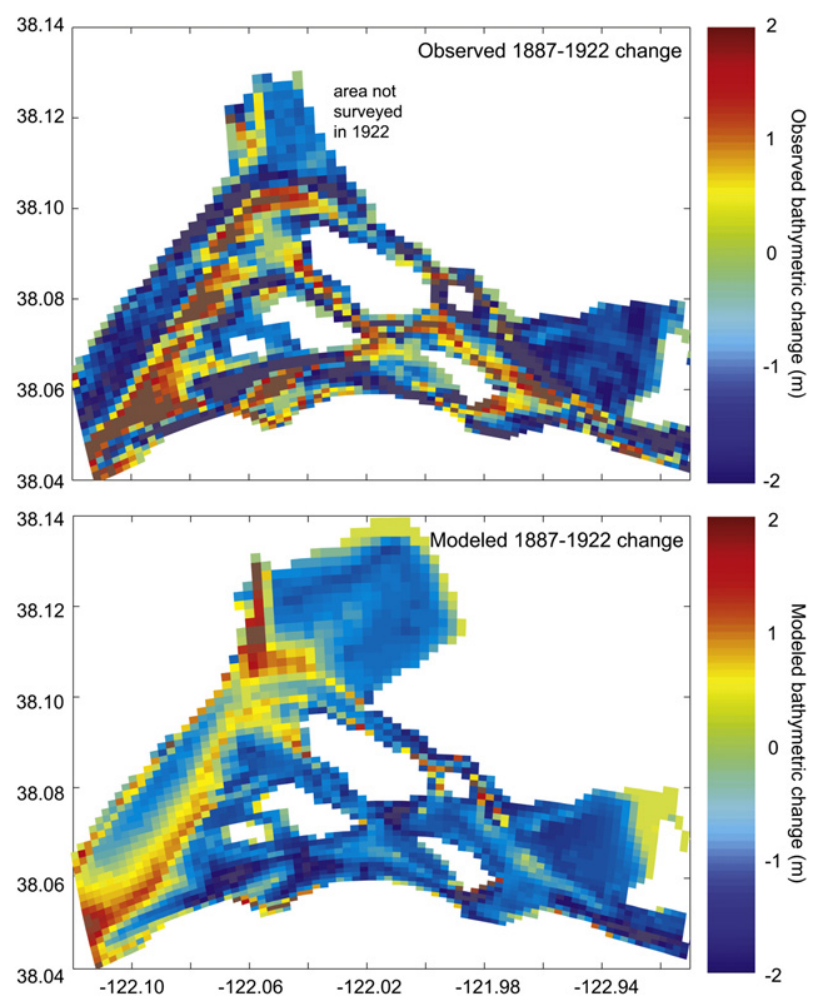

Fig. 3. Observed and modeled bathymetric change for 1887-1922 period.

\subsection{Bathymetric change: $1922-1942$}

For this $20 \mathrm{y}$ period the simulation was performed with $1 \mathrm{y}$ simulation time and $M F=20$; these values were shown to perform adequately for the 1867-1887 period (Ganju et al., 2009). However performance is poor in terms of skill score and sediment budget (Table 2, Fig. 6). Erosion is overestimated in the shallowest $2 \mathrm{~m}$ while net erosion is underestimated. In addition the skill score was negative over most of the depth intervals, which indicates poor spatial agreement. Qualitatively, there are few areas that appear to have reasonable spatial agreement (Fig. 4). Areas of alternating erosion and deposition in Honker Bay are reproduced but changes in the seaward and landward ends of the main channel are poorly simulated.

Agreement was improved in terms of bed change by reducing the seaward SSC boundary condition, deepening the idealized Delta, and reducing critical erosion shear stress (Tables 2 and 3; Fig. 4). The first two parameters reduce transport into Suisun Bay by reducing seaward sediment supply and increasing Delta trapping of watershed sediment loads. Reducing critical erosion shear stress

Table 2

Performance for bathymetric change over the entire domain and depths less than $2 \mathrm{~m}$, for original and modified simulations.

\begin{tabular}{llrrrr}
\hline Period & $\begin{array}{l}\text { Observed Original } \\
\text { change } \\
(\mathrm{m})\end{array}$ & $\begin{array}{l}\text { simulation } \\
(\mathrm{m})\end{array}$ & Error (\%) & BSS & $\begin{array}{l}\text { Modified } \\
\text { simulation } \\
(\mathrm{m})\end{array}$ \\
\hline Entire basin & & & Error (\%) BSS & \\
$1887-1922-0.48$ & -0.37 & $23 \%$ & $0.24-$ & - & - \\
$1922-1942-0.25$ & 0.02 & $108 \%$ & $-0.28-0.16$ & $36 \%$ & -0.62 \\
$1942-1990-0.86$ & 0.18 & $121 \%$ & $0.15-0.63$ & $27 \%$ & 0.17 \\
Depths $<2 \mathrm{~m}$ & & & & & \\
$1887-1922-0.91$ & -0.65 & $29 \%$ & $0.43-$ & - & - \\
$1922-1942-0.14$ & -0.28 & $100 \%$ & $-0.34-0.09$ & $36 \%$ & -0.40 \\
$1942-1990-0.81$ & -0.27 & $67 \%$ & $0.60-0.83$ & $2 \%$ & 0.40 \\
\hline
\end{tabular}



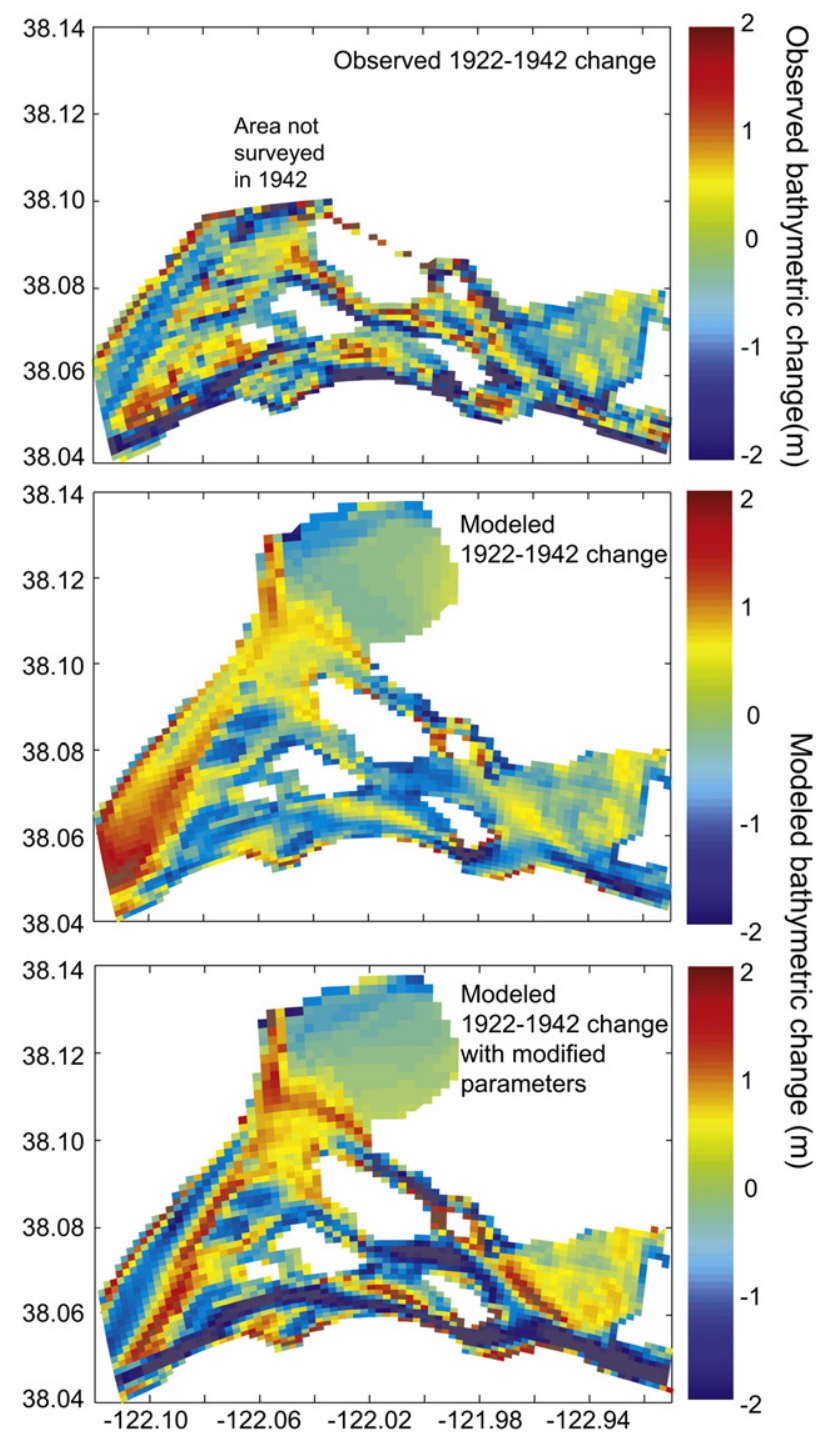

Fig. 4. Observed and modeled bathymetric change for 1922-1942 period. Model performance was improved by modifying Delta and sediment parameters (bottom panel).

mainly altered the within-Bay redistribution of sediment, reducing erosion in the shallowest $2 \mathrm{~m}$ and increasing erosion in deeper areas. Spatial patterns are improved for the seaward end of Suisun Bay though skill scores did not improve. The rationale for these model modifications is addressed in the discussion.

\subsection{Bathymetric change: $1942-1990$}

For this $48 \mathrm{y}$ period the simulation was performed with $1 \mathrm{y}$ simulation time and $M F=48$, and a 2 y simulation time with $M F=24$. Simulations with $M F=48$ produced slightly greater error (not shown), though both sets grossly underestimated net erosion

Table 3

Parameters modified and implemented for model improvement.

\begin{tabular}{|c|c|c|c|}
\hline Parameter & Original value & 1922-1942 value & 1942-1990 value \\
\hline Seaward SSC (\% of original) & $100 \%$ & $50 \%$ & $22 \%$ \\
\hline Critical shear stress $(\mathrm{Pa})$ & $0.15 / 1.05$ & $0.10 / 0.70$ & $0.15 / 1.05$ \\
\hline Mean Delta depth (m) & 3.6 & 4.4 & 5.0 \\
\hline Wave period (s) & 1.425 & 1.425 & 1.65 \\
\hline
\end{tabular}

(and produced net deposition over the entire domain). While BSS was high in the shallowest interval $(0.60)$ erosion was underestimated by over $0.5 \mathrm{~m}$ (Fig. 5). This is due to agreement for phase (i.e., whether a location is erosional or depositional) though agreement is poor for amplitude (magnitude of erosion or deposition). This demonstrates the importance of using multiple metrics for evaluation (Fig. 6).

Visual inspection of the bathymetric changes indicates overestimation of deposition in most areas with agreement in deeper portions of the landward channel and in some areas of Honker Bay (Fig. 5). Changes in the seaward end of the main channel are poorly simulated. Observed erosion near the entrance to Grizzly Bay is also not simulated well.

Agreement was improved in terms of erosion values by further reducing the seaward SSC boundary condition and deepening the idealized Delta (Tables 2 and 3; Fig. 5); further reducing critical erosion shear stress did not improve performance. The overall decrease in sediment supply from both the landward end (due to increased trapping in the Delta) and the seaward end (due to less transport from San Pablo Bay) led to a nearly domain-wide increase in erosion. Skill is changed minimally while net erosion and
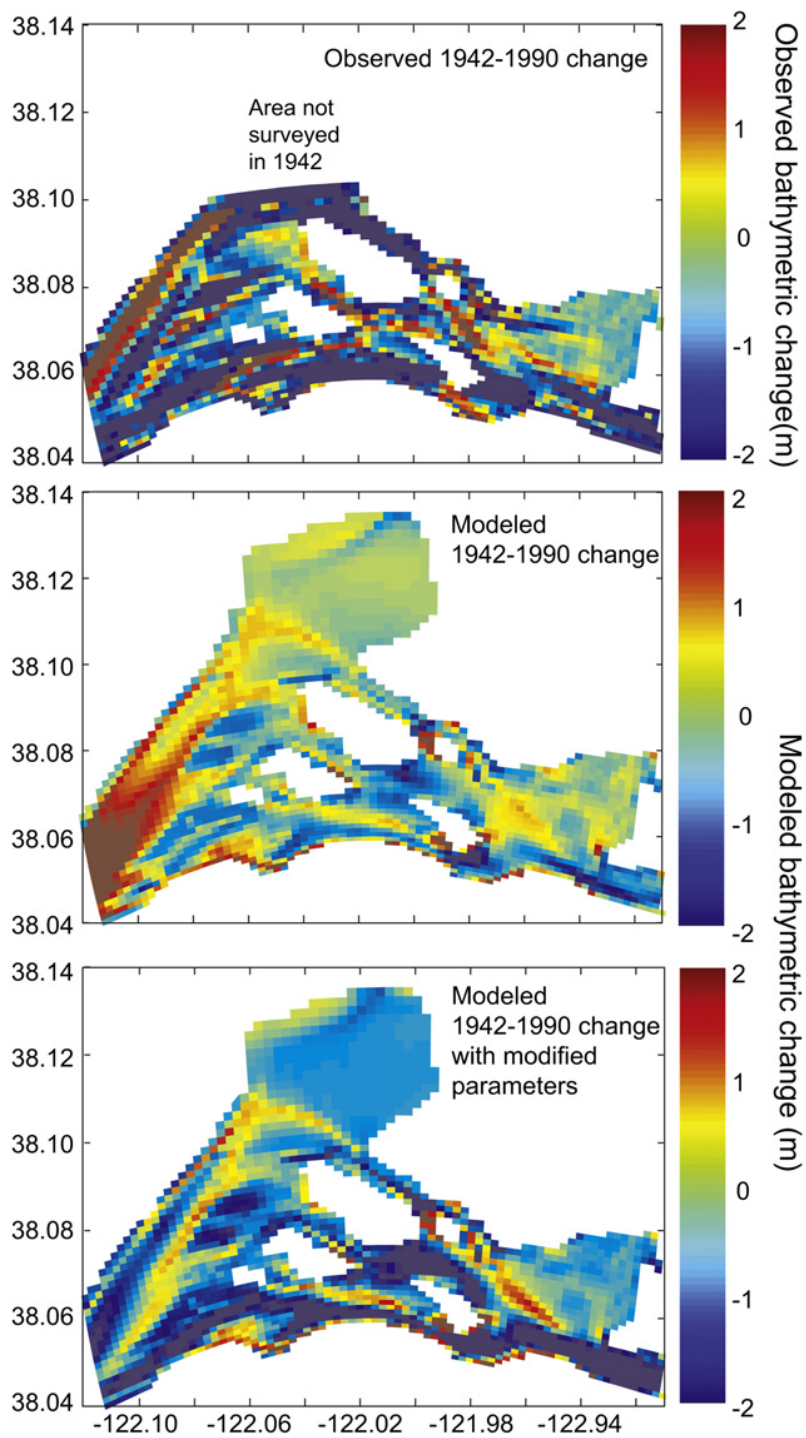

Fig. 5. Observed and modeled bathymetric change for 1942-1990 period. Model performance was improved by modifying Delta and sediment parameters (bottom panel). 


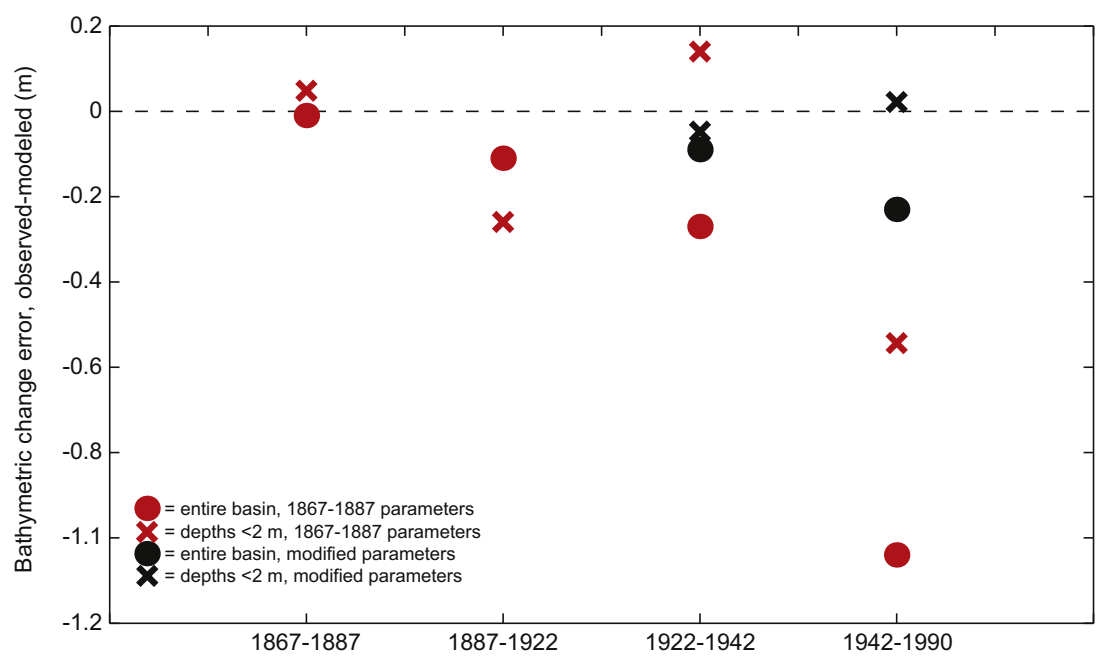

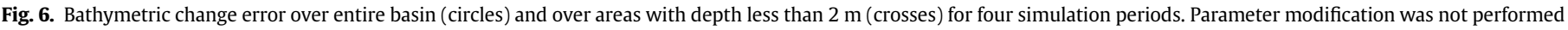
on the 1887-1922 simulation.

deposition are reproduced with substantially less error. The rationale for these model modifications is addressed below.

\section{Discussion}

\subsection{Effect of idealized forcings on model-data agreement}

\subsubsection{Seaward suspended-sediment concentration}

Historical data for SSC were available starting in the 1990's, therefore we extracted the major signals from modern data and applied them to historical years. For SSC this includes the springneap cycle, wind-wave resuspension, and watershed sediment supply. Simulations after 1922 required a reduction in the magnitude of this signal in order to improve performance on a net-basin basis. This is congruent with reduced sediment loads to San Pablo Bay, the seaward boundary of Suisun Bay. As sediment load to San Pablo Bay decreases, sediment availability during the summer wind-wave season should also reduce along with SSC at the Suisun Bay boundary. However, spatial agreement was not improved with this modification (Table 2). The seaward SSC boundary condition clearly improved spatial agreement at the seaward end of the main channel (Figs. 4 and 5); decreases in spatial agreement elsewhere are likely due to modification of sediment bed parameters.

\subsubsection{Sediment bed parameters}

Model parameters such as bed density (or porosity), critical erosion shear stress, and sediment distribution are also variable over decadal timescales. Variations may be caused by consolidation, benthic activity, or changes in sediment type. Benthic composition prior to intensive modern sampling is unknown; in an estuarine environment composition varies spatially and temporally with annual and decadal changes in freshwater flow, sediment load, and salinity. For the 1922-1942 period bed parameters were varied in combination with seaward SSC and Delta depth to obtain better performance with regards to net bathymetric change. In San Francisco Bay Cohen and Carlton (1998) identified the accelerating rate of species invasion starting in the mid-19th century; they suggest that invasive benthic organisms may account for the majority of biomass on or in the sediment bed. This rapid change in biological composition could greatly alter the critical shear stress, porosity, or consolidation dynamics of the sediment bed. In a spatial sense, weakening the sediment bed led to more redistribution within the basin as compared to the original simulation. The redistribution pattern does not match the observations however, and the skill score reflects that. Spatial variability in bed composition is perhaps the most difficult boundary condition to constrain, due to patchiness and the difficulty in characterizing the properties of the bed.

\subsubsection{Landward boundary conditions: Delta configuration and morphological hydrographs}

Prior to 1990 the exact configuration and bathymetry of the Delta are unknown. Throughout the 19th and 20th centuries, dredging, land reclamation, levee construction and natural modifications altered the depths and paths of the numerous channels; the model used here specifies an idealized Delta that can only be crudely modified. We are limited to altering the width and depth of the idealized channel to effectively retain more sediment or allow more sediment to pass through to Suisun Bay. Neither of these modifications can adequately account for the real configuration changes that occurred but data limitations and computational expense preclude specifying the network of channels that comprise the Delta. Therefore it is necessary to alter the idealized Delta's depth in order to match erosion estimates in Suisun Bay during the 1867-1990 period. For the $1922-1942$ and $1942-1990$ periods it was necessary to deepen the idealized Delta (Table 3). This modification trapped more watershed-derived sediment and thereby increased erosion in Suisun Bay in accordance with observations.

In this study we applied three morphological hydrographs that represented dry, intermediate, and wet conditions. These three hydrographs were given equal weight, but in reality the simulated periods may have been better-characterized using unequal weighting. Ganju and Schoellhamer (2010) showed that wetter years with higher flows tended to scour the main channels deposit sediment on channel flanks, while drier years allowed for more sediment import from the seaward boundary. During the 1922-1942 and 1942-1990 periods, spatial improvement may have been improved without modification of seaward SSC and instead by giving more weight to wetter years which would have decreased sediment import on the seaward boundary (Figs. 4 and 5). Further work should investigate the application of morphological hydrographs in idealized domains where the effects can be isolated from other estuarine processes.

\subsubsection{Shoreline configuration}

Bathymetric surveys during 1922 and 1942 did not encompass Grizzly Bay, which is a key location for seasonal sediment storage 
and supply (Krone, 1979; Ruhl and Schoellhamer, 2004). The initial bathymetry of Grizzly Bay is therefore unknown for the 1922-1942 and 1942-1990 simulations and we used the final modeled bathymetry from 1887-1922 and 1922-1942 simulations, respectively, to specify initial conditions. Those results cannot be validated and may affect the overall sediment budget and balance within Suisun Bay. Grizzly Bay comprises 30\% of Suisun Bay; therefore incorrect specification of initial bathymetry can easily confound modeling of net sediment budgets. This may partially account for the superior performance during the 1887-1922 period when initial bathymetry for Grizzly Bay was known. It is critical that geomorphic modeling begins with accurate initial specification of bathymetry over the entire domain, especially over areas capable of storing large volumes of sediment over seasonal timescales.

\subsubsection{Wind-waves}

On the net-basin scale, we modified the idealized wind-wave forcing to improve agreement successfully for the 1942-1990 period (Tables 2,3). Though there are no data to suggest a change in wave energy in Suisun Bay during this period, studies of tidal records on the California coast have shown an increase in "storminess" during the second half of the 20th century (Bromirksi et al., 2002). This storminess is restricted to periods of storm passage (December-March); it is possible that ignoring this signal during the 1942-1990 simulation period has underestimated the erosional contribution of increased wind-waves. The decrease in skill for spatial agreement evidenced by the BSS scores (Table 2, Fig. 6) suggests that the idealized wave field does not adequately represent detailed sediment transport processes. Future work should investigate applying more realistic wave fields complete with morphodynamic updating in comparison with idealized wave fields over static morphology as was done in this study.

\subsection{Implications for long-term geomorphic modeling: ways forward}

Estuaries worldwide are subject to rapid regime shifts in freshwater flow, sediment supply, and benthic composition. Combined with ongoing sea-level rise this implies a constant modulation of hydrodynamic energy and sediment transport behavior. As this study demonstrates, efforts to extrapolate historical or current conditions to simulations of future geomorphology will be fraught with error if parameter space is not investigated in the context of scenarios. For example, to investigate the influence of sea-level rise on estuarine geomorphology, scenarios with and without sea-level rise should be investigated with and without changes in benthic composition (represented by critical erosion shear stress or bed density). Differencing these multiple scenarios then yields the individual effects of each forcing as well as the synergistic effect of the forcings. The results can then be interpreted as a model response to a given set of forcings rather than a "forecast" of future conditions.

Simulations of coastal and estuarine geomorphic change have relied on use of the morphological acceleration factor to reduce computational time and to estimate the long-term effects of estuarine changes. The pioneering work of Latteux (1995), De Vriend et al. (1993), Roelvink (2006), and Lesser et al. (2004) laid a foundation for process-based geomorphic modeling that has identified critical processes and timescales in tidal systems. More recent work has begun to incorporate more nuanced processes such as bank erosion in tidal embayments (Van der Wegen et al., 2008), sea-level rise effects (Dissanayake et al., 2009), and seasonal sediment delivery (Ganju and Schoellhamer, 2010). From this study it is clear that morphological acceleration should be applied with care. During the modeling period actual changes in the estuary (such as dredging, benthic changes, and sediment characteristics) cannot be implemented as the erosional and depositional fluxes are being accelerated. Estuaries which are subject to decadal-timescale shifts in freshwater flow, sediment supply, or benthic composition should not be modeled with morphological acceleration beyond the timescale of those shifts. The choice of simulation time and morphological acceleration factor can interact nonlinearly with annual forcings causing results to vary based on the combination. In tide-only simulations this is not a concern but estuarine sediment transport cannot be modeled properly without inclusion of seasonal sediment delivery, wind-wave resuspension, and residual circulation. These tidal-to-annual timescale processes have not been explicitly evaluated in accelerated models. Recent advances in measurement methods (continuous sediment concentrations, fluxes, bathymetric monitoring) should enable future investigations of multi-timescale processes with advanced hydrodynamic models. The reliability and utility of estuarine geomorphic models can be maximized by applying models to problems on management timescales (i.e., one decade), and testing the sensitivity to the tidal and annual forcing interactions.

\section{Conclusion}

Simulating estuarine geomorphic change over decadal timescales requires data at several temporal and spatial scales. Annual cycles of freshwater flow and wind-waves must be represented while confirmation data usually exists at longer frequencies on the order of decades. We have applied long-term morphological techniques such as morphological acceleration and input reduction (morphological hydrograph) to simulate bathymetric change in Suisun Bay, California. Despite the scarcity of historical data boundary conditions for tides, freshwater flow, salinity, and suspended sediment were generated for the $1887-1990$ period. These boundary conditions capture tidal, annual, and decadal-timescale variability that is due to natural and anthropogenic effects. Simulation of the three bathymetric change periods resulted in varying performance (with parameters held constant) with performance improved by reducing the availability of sediment to Suisun Bay through both the landward and seaward ends, and varying bed parameters. Real changes in sediment availability from the landward (Delta) and seaward (San Pablo Bay) ends of Suisun Bay may be responsible for the necessary changes while benthic composition (due to invasive species) may account for alterations to the sediment bed. This study demonstrates the implementation of morphological simulation techniques with a comparison to field data but also shows the limitations of multi-decadal modeling in systems where parameters are not constant in time. Continuous simulation with constant parameters, in dynamic estuarine systems, therefore appears unrealistic. Extensive sensitivity analyses can constrain model behavior, while simulating multiple scenarios mitigates these errors, and defines model response to individual forcings and their synergy. This work suggests that future estuarine geomorphic modeling should focus on shorter ( $\sim$ one decade) timescales, and investigate the interaction between estuarine processes, idealized forcings and boundary conditions, and morphological acceleration in depth.

\section{Acknowledgments}

This study was supported by the U.S Geological Survey's Priority Ecosystems Science program, CALFED Bay/Delta Program, and the University of California Center for Water Resources. Use of ROMS and the CSTMS was supported by the U.S. Geological Survey, with assistance from John Warner. This article is contribution no. 14 to the CASCADE project (Computational Assessments of 
Scenarios of Change for the Delta Ecosystem, Project \# SCI-05C01-84). Any opinions, findings, and conclusions or recommendations expressed in this material are those of the authors and do not necessarily reflect the views of the CALFED Science Program. The manuscript was greatly improved by the Editor and anonymous reviewers.

\section{References}

Ariathurai, R., Arulanandan, K., 1978. Erosion rates of cohesive soils, Proceedings of the American Society of Civil Engineering. Journal of the Hydraulics Division 104, 279-283.

Bromirksi, P.D., Flick, R.E., Cayan, D.R., 2002. Storminess variability along the California Coast: 1858-2000. Journal of Climate 16, 982-993.

Buchanan, P.A., Ganju, N.K., 2005. Summary of Suspended-sediment Concentration Data in San Francisco Bay, California, Water Year 2003. In: U.S. Geological Survey Data Series 113.

Cappiella, K., Malzone, C., Smith, R., Jaffe, B., 1999. Sedimentation and Bathymetry Changes in Suisun Bay, 1867-1990. In: U.S. Geological Survey Open-File Report 99-563.

Coastal Engineering Research Center, 1984. Shore Protection Manual. U.S. Army Corps of Engineers, Waterways Experiment Station, Vicksburg, Mississippi.

Cohen, A.N., Carlton, J.T., 1998. Accelerating invasion rate in a highly invaded estuary. Science $279,555-558$.

De Vriend, H.J., Capobianco, M., Chesher, T., De Swart, H.E., Latteux, B., Stive, M.J.F., 1993. Approaches to long-term modelling of coastal morphology: a review. Coastal Engineering 21, 225-269.

Dean, R.G., Dalyrymple, R.A., 1991. Water Wave Mechanics for Scientists and Engineers. World Scientific Publishing, Singapore, 353 pp.

Dissanayake, D.M.P.K., Ranasinghe, R., Roelvink, J.A., 2009. Effect of sea level rise in tidal inlet evolution: a numerical modeling approach. Journal of Coastal Research, Special Issue 56, 942-946.

Ganju, N.K., Knowles, N., Schoellhamer, D.H., 2008. Temporal downscaling of decadal sediment load estimates to a daily interval for use in hindcast simulations. Journal of Hydrology 349, 512-523.

Ganju, N.K., Schoellhamer, D.H., 2006. Annual sediment fluxes in a tidal strait using surrogate measurements. Estuarine, Coastal and Shelf Science 69, 165-178.

Ganju, N.K., Schoellhamer, D.H., 2009. Calibration of an estuarine sediment transport model to sediment fluxes as an intermediate step for robust simulation of geomorphic evolution. Continental Shelf Research 28, 148-158.

Ganju, N.K., Schoellhamer, D.H., Jaffe, B.E., 2009. Hindcasting of decadal-timescale estuarine bathymetric change with a tidal-timescale model. Journal of Geophysical Research-Earth Surface 114, F04019. doi:10.1029/2008JF001191.

Ganju, N.K., Schoellhamer, D.H., 2010. Decadal-timescale estuarine geomorphic change under future scenarios of climate and sediment supply. Estuaries and Coasts $33,15-29$.

Gartner, J.W., 1997. Harmonic Analysis Computer Program, Developed by Mike Foreman. Institute of Ocean Sciences, Sidney, BC, Canada, Based on: Foreman, M.G.G. Manual for tidal heights analysis and prediction (66 pp.). Patricia Bay, Sidney, BC: Institute of Ocean Sciences. PMS report, 77-10.
Hibma, A., de Vriend, H.J., Stive, M.J.F., 2003. Numerical modeling of shoal pattern formation in well-mixed elongated estuaries. Estuarine, Coastal and Shelf Science 57, 981-991.

Krone, R.B., 1979. Sedimentation in the San Francisco bay system. In: Conomos, T.J. (Ed.), San Francisco Bay: The Urbanized Estuary, Pacific Division of the American Association for the Advancement of Science, San Francisco, California, pp. 85-96.

Latteux, B., 1995. Techniques for long-term morphological simulation under tidal action. Marine Geology 126, 129-141.

Lesser, G.R., Roelvink, J.A., van Kester, J.A.T.M., Stelling, G.S., 2004. Development and validation of a three-dimensional morphological model. Coastal Engineering 51 883-915.

Madsen, O.S. Spectral wave-current bottom boundary layer flows. In: Proceedings, 24th International Conference Coastal Engineering Research Council, 384-398, 1994.

Murphy, A.H., Epstein, E.S., 1989. Skill scores and correlation coefficients in model verification. Monthly Weather Review 117, 572-581.

Roelvink, J.A., 2006. Coastal morphodynamic evolution techniques. Coastal Engineering 53, 277-287.

Ruhl, C.A., Schoellhamer, D.H., 2004. Spatial and temporal variability of suspendedsediment concentrations in a shallow estuarine environment. San Francisco Estuary and Watershed Science 2 (2) article 1.

Schoellhamer, D.H., Lionberger, M.A., Jaffe, B.E., Ganju, N.K., Wright, S.A Shellenbarger, G.G., 2005. Bay Sediment Budgets: Sediment Accounting 101. The Pulse of the Estuary: Monitoring and Managing Contamination in the San Francisco Estuary. San Francisco Estuary Institute, Oakland, California. 84 p..

Shchepetkin, A.F., McWilliams, J.C., 2005. The Regional Ocean Modeling System (ROMS): a split-explicit, free-surface, topography-following coordinates ocean model. Ocean Modelling 9, 347-404.

Sutherland, J., Peet, A.H., Soulsby, R.L., 2004. Evaluating the performance of morphological models. Coastal Engineering 51, 917-939.

Thompson, J., 1957. The settlement geography of the Sacramento-San Joaquin Delta, California. Ph.D. dissertation, Stanford University.

Van der Wegen, M., Dastgheig, A., Jaffe, B.E., Roelvink, J.A., 2010. Bed composition generation for process-based morphodynamic modeling: case study of San Pablo Bay, California. Ocean Dynamics. doi:10.1007/s10236-010-0314-2.

Van der Wegen, M., Roelvink, J.A., 2008. Long-term morphodynamic evolution of a tidal embayment using a two-dimensional, process-based model. Journal of Geophysical Research 113, C03016. doi:10.1029/2006JC003983.

Van der Wegen, M., Wang, Z.B., Savenije, H.H.G., Roelvink, J.A., 2008. Long-term morphodynamic evolution and energy dissipation in a coastal plain, tidal embayment. Journal of Geophysical Research 113, F03001. doi:10.1029/2007JF000898.

Wahba, G., 1990. Spline Models for Observational Data. Society for Industrial and Applied Mathematics, Philadelphia, PA. 169 p.

Warner, J.C., Geyer, W.R., Lerczak, J.A., 2005. Numerical modeling of an estuary: a comprehensive skill assessment. Journal of Geophysical Research 110, C050001.

Warner, J.C., Sherwood, C.R., Signell, R.P., Harris, C.K., Arango, H.G., 2008. Development of a three-dimensional, regional, coupled wave, current, and sedimenttransport model. Computers and Geosciences 34, 1284-1306.

Wright, S.A., Schoellhamer, D.H., 2005. Estimating sediment budgets at the interface between rivers and estuaries with application to the Sacramento-San Joaquin River Delta. Water Resources Research 41, W09428. doi:10.1029/ 2004WR003753. 